\title{
The Teach-to-the-Test Approach: Doing Harm to the Lifelong Educational Paradigm of Algerian EFL Learners
}

\section{Smail Benmoussat, Nabil Djawad Benmoussat}

Department of English, Faculty of Letters and Languages, University of Tlemcen, Tlemcen, Algeria

Email address:

smail11256@yahoo.co.uk (S. Benmoussat)

\section{To cite this article:}

Smail Benmoussat, Nabil Djawad Benmoussat. The Teach-to-the-Test Approach: Doing Harm to the Lifelong Educational Paradigm of Algerian EFL Learners. English Language, Literature \& Culture. Vol. 3, No. 1, 2018, pp. 1-6. doi: 10.11648/j.ellc.20180301.11

Received: December 30, 2017; Accepted: January 20, 2018; Published: February 6, 2018

\begin{abstract}
The present paper is a plea for a reconsideration of the boundaries of EFL teaching and testing within the framework of the lifelong educational paradigm. Today the educational arena dictates a new paradigm in which lifelong learning becomes indispensable. Learning is no more confined to a specific physical context: the classroom; it goes beyond the school gates. The traditional limits on where and when organized knowledge could be imparted as part of a pre-service or inservice training no longer apply. Lifelong learning has become a sine qua non condition for the establishment of a learning society. Yet, as for English Language Education, two antagonistic approaches arise. The first in which parents would most probably argue about what is best to be taught to their children as well as about the most appropriate and effective learning path leading to their offspring success in an increasingly complex world, whereas the second, in which teachers strive to cope with a delicate intertwined questioning of how to strike the balance between an effective teaching and an efficient testing. True, EFL learners in Algeria are in most need of a well-rounded education. An English Language Education geared by the "learning-how-to-learn" principle paving therefore the way for a lifelong educational paradigm.
\end{abstract}

Keywords: EFL Teaching-Testing, Lifelong Learning, Learning Society, English Language Education, Learning How to Learn

\section{Introduction}

Today's globalized world is characterised by an increasing demand for education. Since 1948, education has been universally proclaimed as a human right ${ }^{1}$ with a multidimensional perspective. Education, in its comprehensive sense, can be extended to cover the field of language learning, not least English Language Education. This relentless demand, an inherent characteristic of the post-war

\footnotetext{
1 The right to education is one of the human rights proclaimed in the Universa Declaration of Human Rights (1948). a) Everyone has the right to education. Education shall be free, at least at the elementary and fundamental stages. Elementary education shall be compulsory. Technical and professional education shall be made generally available and higher education shall be equally accessible to all on the basis of merit. b) Education shall be directed to the full development of the human personality and to the strengthening of respect for human rights and fundamental freedoms. It shall promote understanding, tolerance and friendship among all nations, racial or religious groups, and shall further the activities of the United Nations for the maintenance of peace (Universal Declaration of Human Rights, art. 26/1 and 26/2).
}

period, is due to the major noble mission which education can be assigned in affording societies with functional and responsible citizens who, in turn, are expected to contribute positively and significantly to the development of their nations and to meet the requirements of an ever increasing process, globalization. Bolitho notes that, "In educating the citizens of tomorrow, we are told, we should be preparing them to cope with change in our increasingly globalised world" [1].

Undeniably, education is becoming a platform or rather a springboard, in the establishment of a knowledge society ${ }^{2}$, a society in which the new source of power is not money in the hands of the few, but information in the hands of many [2]. It

\footnotetext{
2 The notion of "knowledge society" emerged towards the late 1990s and is particularly used as an alternative by some in academic circles to the "information society". Yet there has been a great deal of reflection on the issue. UNESCO views "information society" as the building block for knowledge societies. Information society is to be linked to the idea of technological innovation. It designates a particular vision of developments arising from an optimal use of ICT's in the storage and processing and dissemination of information.
} 
is to this end that the quality of education has become a must giving way to the notion of 'high-quality education, ${ }^{3}$ which will motivate and inspire lifelong learning. This new $21^{\text {st }}$ century-vision of education, with teacher effectiveness as a key component and learner involvement as an active partner, would lead to reconsider and redraw the boundaries of language teaching and language testing within the construct of the communicative abilities of Algerian EFL learners beyond the school gates. Mapping out the configuration of lifelong learning is no easy task, yet to get started "Teachers must take their place again among the society's most respected intellectuals, moving beyond the citadel of the classroom to being, and preparing their students to be citizens of the world [3].

\section{In Search for an Appropriate Methodology}

The changes that English Language Education has witnessed, from a teacher-centred pedagogy to a more learner-centred education, from a textbook-based teaching to a task-based approach, from a summative assessment to a formative assessment [4], reflect educators commitment and teachers concern in an effort to find an appropriate methodology which best relates teaching to testing on a communicative continuum. Yet the problematic has not yet been resolved even after decades of continual change, update, and improvement of the English Language Teaching Methodologies. Even worse, the issue has reached a critical state when the main concern of both parents and the educational institution is shifting from students potential and academic development to students achievement in exams. In this sense, the word 'achievement' means nothing more than scoring well on standardized tests and high-stakes exams ${ }^{4}$ such as the Baccalaureate exam which is an illustrative instance of what a high-stakes test is.

\subsection{The Baccalaureate: A High-Stakes Exam}

The Baccalaureate examination, as an achievement test, plays an important role in the Algerian education system at large. It usually takes place in June. This end-of-year period is a very stressful for stakeholders, mainly students, teachers, school administrators and parents. Since its inception in 1963, the Baccalaureate examination has always been a lever for change $e^{5}$ to initiate educational reforms in an effort to

3 'High-quality education', as a comprehensive term, has been since its early use in Tomorrow's schools (1995) the subject of much discussion and heated debates among educators. Any attempt to give a valid definition to 'high-quality education' would distort its nature and therefore would be too vague and oversimplistic. It is an elusive term. Green ironically yet illustratively defines it with reference to the "education that the rich provide for their sons" [5].

4 High-stakes exams are so important in the eyes of many stakeholders in the sense that their results, as Madaus notes "are seen, rightly or wrongly, by students, teachers, administrators, parents, or the general public, as being used to make important decisions that immediately and directly affect them" [6].

5 Tests are frequently used as a means to engineer innovation, to steer and to guide the curriculum [11] (Alderson, 2004). Tests are, all too often, intended as establish academic standards and a more or less reliable source of information on educational outcomes to external stakeholders. Its preparation starts early in the school year, sometimes even a few years beforehand. It has a reputation for being a thorough summative assessment. What is more, the over importance assigned to the bureaucratic nature of the Baccalaureate in the Algerian education system has paved the way for the emergence of a new philosophy. This philosophical conception is rendering teachers even more cynical about the rate of success in the Baccalaureate exam, and devising ways of turning it to productive account for both teachers and learners.

\subsection{Teach-to-the-Test Approach}

This cynical dimension would lead us to touch on another aspect of the teach-to-the-test approach: the coaching services that are offered outside school time and school walls by teachers. These so-called extra remedial lessons, oriented chiefly towards practicing exam techniques have turned to become commonplace and a very trendy form of outsideschooling. Students spend evenings, weekends, and winter and spring holidays preparing for the Baccalaureate exam in teachers' homes, or even in garages. The following quotation illustrates clearly the rationale, so to speak, underlying such tendency, "The benefits of such a compensatory teaching are wide-range: the number of students is very limited, the teacher explains every single word or structure in Arabic or in French, he goes through the exercises that were done in the classroom and the pupil has all the chances to succeed. That's an extra to teachers to make ends meet" [7]. True, this type of supplementary education costs a great deal of money, and yet students' families willingly or unwillingly try to 'keep up with the Joneses', to use an appropriate idiomatic expression.

On the other hand, most teachers report that they try to follow the textbook only during the first two terms of the year, and many schools stop giving courses and classroom dissolved right before the spring holidays so that students can study on their own. However, in some schools the third term is devoted to a greater use of past papers and commercial exam-related publications. This raises the issue why teachers at this period of the year rely extensively on exam-oriented materials and past papers. As Spratt notes, "they [teachers] wish to fulfil student expectations or their presumed expectations" [8]. This test-oriented teaching is manifested by the students insistence on doing practice tests. Teachers do this as "they believe the best way to prepare students for exams is by doing past papers" [9]. This teaching-to-the-test approach, based on Underhill's preach "As ye teach, so shall ye test' [10], has led to the publication and proliferation, on a large scale, of annals containing materials that are highly exam-technique oriented. Yet, from an educational standpoint, it is believed that this pedagogical approach encourages teachers to focus much more on individual

levers for change. The challenge resides in how to make such mechanism consolidate and reinforce the teaching and learning of skills that are conducive to a betterment of the education system at large. 
language items and grammar structures rather than engage students in an integrated cyclical learning process. In this way, the textbook becomes a test-book and therefore loses not only its intrinsic value but also many of the attributes which have been assigned to it. This 'unhealthy' and 'unethical' and counter-productive teaching has led to the implementation of the principles of the teach-to-the-test approach $^{6}$ forcing, in one way or another, teachers to focus their time, effort and energy on preparing learners for tests in order to raise test scores.

\section{Testing: A Necessary Evil}

To better understand what is actually wrong with the teach-to-the-test approach, one needs to dig deeper in order to realize how the relationship between teaching and testing ought to be. No one would deny the fact that testing is a vital component of any instructional programme throughout the world; it has always been viewed and labelled as a 'necessary evil', yet as a means to promote and assess learning. This paradoxical assertion would lead us to state unambiguously that teaching and testing are closely interrelated and complete each other in the sense that there is no testing without teaching nor is there teaching without testing. In an analogical way, they are two facets of the same coin. However, the increasing focus on exam performance has accentuated the pressure on teachers and geared them towards a selective-focussing teaching and caused them to do deliberately great harm to the broader learning process. However, to function properly, a test is supposed to assess the teaching/learning process at large; narrowly speaking, it is bound to provide a way to measure students' demonstration of learning, qualitatively, i.e. how well and quantitatively, i.e. how much. In very practical terms, a test helps answer a triadic-oriented question: How much did the students learn? How well did they learn it? And, how well did we teach it? In this sense, the test should reflect what was taught in order to be a reliable and a valid one. To meet these goals, teachers need to be familiar with the general guidelines and have a sound knowledge of the key concepts underpinning the different test-types. Such familiarity and mastery will serve as a platform, or rather a springboard for teachers, especially novice and less experienced, to devise a practical test which can be relied on so as to yield valid indices about the learning progress as well as the teaching process.

\subsection{Teaching and Testing: Two Sides of the Same Coin}

Arguably, if the interplay between teaching and testing follows a logical sequence based on the teaching of what will be tested, or more precisely, a selective focussing on the teaching items of the test, the cause and effect relationship resulting from the two processes will cause considerable harm to the learning process as a whole. A test cannot cover

6 In the mind of many applied linguists, educators and teachers 'item teaching', 'curriculum teaching' and 'teaching-to-the-test' are all too often used interchangeably. all items that are prescribed in the curriculum, in this sense, what will not be in the test will not be taught, or at least will not be given much importance or eventually put apart. Hence, a domino-like effect arises: the test will lose its validity; the teaching will lose its credibility and the curriculum will lose its intrinsic value. Yet, But why do teachers are at times bound to follow the teach-to-the-test approach? It is important to know that teachers' conviction to use this approach is due to two main reasons: one pedagogical and the other societal.

The pedagogical dimension closely relates to the fact that virtually all teachers point out the overloaded curricula for which they are bound to cover in due time. This time constraint leads teachers to engage in a selection of only those items that likely to feature prominently in exams rather than to teach effectively and with pace according to their learners degree of intake and assimilation. The societal dimension is due to the fact that both parents and the academic institution give too much importance and great value to the result obtained by their students. In other words, and in terms of accountability, the education institution in general and teachers in particular are judged in relation to their students' success and achievement in exams, not least high-stakes exams, such as the Baccalaureate exam. Since independence in July 1962, scores obtained in standardized tests have served as a 'benchmark' to compare and rank educational institutions throughout the country. In sum then, standardized testing is still regarded as a large-scale measure of schools effectiveness.

\subsection{Teacher's Connivance}

To play safe and, paradoxically, in an effort to satisfy the stakeholders' policy and to abide by loyally the education institution's rules of the game, the teachers, caught between a rock and a hard place, generally play the game and have recourse to the teach-to-the-test approach. This teaching practice is acknowledged to negatively impact the teaching/learning process, and in consequence, calls into question the credibility of the educational system as a whole. A focus on the quality of education is as crucial as ever, with tests levers for change. What is more, most educators and linguists agree that, at present, tests are no more testing learners' knowledge and potentials, but testing their ability to reproduce fixed bodies and exact structures of knowledge [12]. This form of testing runs against the basic principles of quality education ${ }^{7}$. As a result, schools are no more those

7 Two different concepts relate to the question of quality in education: positivism and constructivism. "Positivist orientations to learning emphasize the acquisition of facts, while constructivist orientations emphasize the interpretation of facts and the construction of knowledge. Until very recently, education systems in most countries have been based firmly o positivist principles, featuring the teacher at the center of the instructional process transmitting information through 'chalk and talk' to students, primarily for the purposes of memorization. Since memorizing information is no longer regarded as adequate learning, and analytical skills are increasingly in demand, many countries have recently adopted reforms or new paradigms of teaching and learning based on constructivist principles" [13]. The locus of studies in the $21^{\text {st }}$ century is shifting towards skills acquisition rather than knowledge accumulation. This skills-acquisition pedagogy serves as a 
educational institutions with sole attributes encouraging meritocracy and scholastic advancement for those highly motivated and talented students. Even worse, many individual learners, without learning opportunities, cannot develop the competencies and skills that will help them use the language communicatively. Regretfully, one might say that testing, which ought to be the pedagogical tool to assess and promote learning, has lost its intrinsic value and acts as an overt deteriorating element in a teaching approach.

\subsection{Lack of Communicative Abilities}

The teaching-to-the-test approach has now become commonplace and its alarming wide spread use has touched many educational institutions worldwide, and the Algeria education system is no exception. The major goal underpinning English teaching in Algeria is to make learners able to communicate, express their ideas, argue, maintain discussions and avoid discussion breakdowns. Yet, sometimes, what is prescribed as objectives and goals is just ink on paper. Unfortunately, at present time, the immediate goal and the principle motivating drive pupils to learn English is to pass examination. This shift in interest has led to the emergence of successful learners on exam seats but ineffective and very incompetent ones in real life context. Moreover, the success of learners in high-stakes exams, such as the Baccalaureate exam, will afford them an opportunity to enter university and embark on a higher education. As an immediate deleterious result, EFL teachers at university level will find themselves facing students who only excel in reproducing faithfully exact forms of knowledge in exam seats rather than having considerable skills in dealing with the language communicatively.

\section{In Search for a Remedial Approach}

Arguably, between the demands for high-quality education and the many issues of how to teach effectively and how to test efficiently, a radical change is indeed a necessary step to take further. However, up to there, teachers need to adopt remedial approaches in an effort to make up for the damages resulting from an over use of the-teach-to-the-test approach. University teachers, for instance, need to rethink about reassessing their students to know their students' true colours in terms of language background; they also need to redraw the frames of their lectures to compensate for their learners weaknesses, and ultimately devise new ways for assessing their new acquired knowledge using more attractive alternative assessment procedures such as project-based learning and portfolios ${ }^{8}$. This challenging situation is of

springboard for autonomous self-directed and lifelong learning.

8 Portfolios are collections of various assignments that students have compiled over a period of time, a term, a semester or an academic year. From a pedagogical standpoint, a portfolio denotes "a purposeful collection of any aspect of the students' work which is kept in a file folder, box, ... that tells about the students' improvement, progress, and achievement"[14]. Unlike the traditional assessment procedures, portfolio assessment enables learners to actively participate in the evaluation process of their own work (learner-centred assessment). paramount importance if an education of high quality is to be reached, and the washback ${ }^{9}$ effect of the teaching-to-the-test approach to be reduced.

\subsection{Algeria's EFL Policy and Lifelong Education}

Like many other countries, Algeria has adopted English as a foreign language in her schools and higher educational institutions. Although English is seen as a vehicle conducive to economic development, technological advancement and commercial expansion, it has no established functions in the country; officially, it is considered to have equal status with the other foreign languages, namely Spanish and German. However, the recent changes in the country's politico-economic policies have borne heavily on the creation of a new learning/teaching milieu for the learning of the English language. One might argue that, with the development of many new opportunities for private businesses, and the multiplication of joint ventures with foreign companies resulting from the on-going globalization process, the English language in Algeria will be assigned a higher status.

It must be acknowledged that, particularly since the late $1990 \mathrm{~s}$, there has been a great increase in the number of 'outside' short English courses offered by private schools. Yet in such institutions, one faces widely varying situations, but there are some common elements running through all of them. In general the learners are highly motivated, but it is a motivation towards practical use of the language. The idea that language is an effective key to the understanding of another culture interests only a minority; we are still a long way from that goal. However, the growing demand for English as the sole vehicle conducive to economic development, technological advancement and commercial expansion has led to interesting changes in the politico-linguistic orientation of Algeria's language planning policy. As mentioned by Crystal, there has never been a language so widely spread and spoken by so many people as English [19]. This has given rise to the assumption that English is more the property of the inner circle, to use Kachru's (1986) term [20]; it belongs to whoever

9 Much has been written about the influence of testing on teaching and learning. "Public examinations influence the attitudes, behaviours, and motivation of teachers, learners and parents, and because examinations often come at the end of a course, this influence is seen working in a backward direction, hence the term, washback. Washback or backwash, a term now commonly used in the testing literature, refers to the influence of testing on teaching and learning [15]. Alan Davis, the doyen of British language testing, frequently used the term washback and I do not recall him ever using backwash... to clarify the distinction between the terms backwash and washback: there is none. The only difference is that if somebody has studied at the University of Reading, UK, where Arthur Hughes used to teach, they are likely to use the term backwash. Hughes states simply that: "the effect of testing on teaching and learning is known as backwash" [16]. If they have studied language testing anywhere else, but especially in Edinburgh or Lancaster in the UK, they will almost certainly use the term washback [17] (Alderson, cited in Cheng \& Watanabe). However, Andrews comments on the backwash versus washback nomenclature. Based on his own review of the literature, he comments that: "in general education literature, the favoured term to describe this phenomenon is 'backwash', while in language education there seems to be a preference for "washback" [18]. 
uses it for whatever purpose or need [21].

\subsection{The GVC Experience}

Arguably, the new technologies are significantly changing the face of education at various levels. E-learning, with its wide-range use of ICT's applications outside the classroom, will have the lion's share in the context of lifelong education. In Algeria, the internet is steadily gaining ground; it is becoming the foremost medium of self-instruction and a tool towards the development of learner autonomy. What is more, the advent of virtual classrooms, such as the Global Virtual Classroom, or GVC for short, located at the University of Tlemcen, has contributed successfully to the promotion of language programmes and cultural exchanges on formal and informal bases with students from many parts of the world. In the long-run, the GVC's e-learning language and cultural programmes are expected to bring about radical changes in the pace of lifelong learning. This will, hopefully, contribute to the promotion of foreign language learning, not least English Language Education.

\section{Conclusion}

Learning for no obvious reason, or at least, learning for passing exam purposes have no raison d'etre in the educational framework prescribed by the principles underlying sustainable learning societies. As for English as a subject matter, it is generally thought of as an examination subject rather than a necessary component in the general education programme; a vital vehicle conducive to the buildup of a sustainable information society. However, the immediate goal of and the primary motivating force in learning English in Algeria is to help pupils and students pass examinations. Indeed, informants almost overwhelmingly cite passing exams as the primary motive for studying English. This exerts a pernicious influence on the language learning process in the sense that English language education is regarded as an end in itself.

The overall educational failure of the Algerian School and lack of achievement in the English language learning field affecting negatively the pupils attitudes and motivation towards the new language can be traced back mostly to two types of factors: endogenous and exogenous factors. The endogenous factors deserve careful examination; they have, one might say, a significant pedagogical dimension. Success in language learning can, to a greater extent, be attributed to their optimal mix input. The endogenous factors fall into four interrelated set-backs: teaching staff, learners attitudes and motivation, physical conditions, and curricula of textbooks. The exogenous factors, however, are closely related to the status of English as a foreign language. A language's importance is closely related to its use outside school gates. It is worth noting that a cause-and-effect relationship can be established between macro-economic factors and language proficiency. A language which is spoken by rich countries is more attractive to learners than one which provides no access to personal betterment or lucrative markets [22]. In very down-to-earth-terms, the language of an economically strong community is attractive to learn because of its business potential. It is clear that the growing number of people expressing their desire towards learning English as well as the growing number of schools, state-run or private, offering courses mirror the place the English language holds in various fields worldwide. This confirms what Ibn Khaldun posited more than some six centuries ago in his El Mukkkadima (1372) that the triumph of a language reflects its speakers' triumph and its position among languages expresses its position among nations [23].

Within the globalization framework, the transition from a literate society to a knowledge society is no easy task; it is a matter of a systematic metamorphosis. The Algerian University, being an oasis of knowledge centres, is bound up to play a fundamental role to guarantee lifelong learning. True, lifelong learning has become is a key concept in the education literature. Not only does it bear strong ties with the country's economy, but it is highly related with language development of the individual as well. The newly-assigned mission to higher-education institutions in Algeria creates new and tremendously important demands and exigencies. Some of these requirements cannot be obtained without first and foremost a good working knowledge of the English language, not least, English for Specific Purposes (ESP). Scientific research and optimal use of new ICT's are crucial activities and sine qua non conditions to successfully implementing lifelong education paving therefore the way to the steady building up of a knowledge society ${ }^{10}$. Such rapprochement denotes how important are English language learning and lifelong learning for a steady build-up of a knowledge and information-driven society within the globalization framework. Yet, what is the place of highquality education, or at least basic education, in the context of lifelong learning [24]. This neglected aspect of education is a prerequisite for a lifelong learning scheme and a sustainable knowledge society.

\section{References}

[1] BOLITHO, R. (2012). Projects and Programmes: Contemporary Experience in ELT Change Management. In HORNBERGER, N. H (Ed.) (2008) Encyclopedia of Language and Education, $2^{\text {nd }}$ Edition Springer, p. 35.

[2] NAISBITT J. (1982). Megatrends: Ten New Directions Transforming Our Lives. Warner Books: Warner Communications Company.

[3] HARGREAVES, A. (2003). Teaching in the Knowledge Society: Education in the Age of Insecurity. Teachers College Press. Columbia University. New York, p. 2.

10 Within today's globalized world, the knowledge society is also viewed as the 'good-will ambassador of globalization' and the development of globalization has been associated with the dominance of the English language. While it can be also be noted that, 'The power and influence of English have been widely recognized nowadays in the context of globalization' [25]. This is another way of saying that 'Globalization has contributed to the spread of the English language ... the English language is itself an agent of the spread of globalization' [26]. 
[4] KO, P. Y. (2000). From Enthusiasm to Caution. In B. ADANSON, T. KWAN and K. K. CHAN (Eds) Changing the curriculum: The impact of Reform on Primary Schooling in Honk Kong. Honk Kong: Honk Kong University Press.

[5] GREEN, T. (1980). Predicting the Behavior of the Education System. Syrawse MY: Syrawse University Press, p. 120.

[6] MADAUS, G. F. (1988). The Influence of Testing on the Curriculum. In TANNER, L. N. (Ed) Critical Issues in Curriculum: Chicago: University of Chicago Press, p. 87.

[7] BENMOUSSAT, S. (2003). Mediating Language and Culture: An Inverstigative Analysis of the Cultural Dimension in the Algerian Newly-Designed ELT Textbook. Unpublished Doctorat d'Etat Thesis, Abou Bakr Belkaid University, Tlemcen.

[8] SPRATT, M. (2005). Washback and the Classroom: the Implications for Teaching and Learning of Studies of Washback Exams. Language Teaching Research 9(1) 5-29.

[9] LAM, H. P. (1994). Methodology Washback: An Insider's View. Bringing About Change in Language Education. Honk Kong: University of Honk Kong (83-99).

[10] UNDERHILL, N. (1982). The Great Reliability Validity Trade-off: Problems in Assessing the Productive Skill. In Heaton, J. B. (Ed) Language Testing Modern English Publications, London, 17-23.

[11] ALDERSON, J. C. (2004). Foreword, in: L. Cheng and Y. Watanabe, with A. Curtis (Eds.) Washback in Language Testing: Research Contexts and Methods (Mahwah, NJ and London, Lawrence Erlbaum Associates), ix-xii.

[12] SCHWEISFURTH, M. (2011). Learner-Centered Education in Developing Country Contexts: From Solution to Problem? International Journal of Educational Development 3/ 419-26.

[13] LEU, E. (2005). The Role of Teachers, Schools, and Communities in Quality Education: A Review of the Literature. Academy for Educational Department, Global Education center, Washington.
[14] JAVANMARD, Y and FARAHANI, H. (2012). Investigating Using Portfolio Assessment and Learning English Language in Qum Secondary Schools. Global Journal of Human Social Sciences, Vol. 12, p. 53.

[15] ALDERSON, J. C. and WALL, D. (1993). Does Washback Exist? Applied Linguistics, 14(115-129).

[16] HUGHES, A. (2003). Testing for Language Teachers $\left(2^{\text {nd }}\right.$ Ed.) Cambridge: CUP, p. 1.

[17] CHENG, L. and WATANABE, Y. (2004). Washback in Language Testing: Research Contexts and Methods. London: Lawrence Erlbaum Associated, Publishers, pp. xi-xii.

[18] ANDREWS, S. (1994). The Washback Effect of Examination: Its Impact Upon Curriculum Innovation in English Language Teaching. Curriculum Forum 4(1), 44-58.

[19] CRYSTAL, D. (1997). English as a Global Language. Cambridge: Cambridge University Press.

[20] KACHRU, B. B. (1986). The Alchemy of the English Language. Oxford: Oxford University Press.

[21] HASMAN, M. (2000). The Future of English? A Guide to Fostering the Popularity of the English language in the $21^{\text {st }}$ Century. London: The British Council.

[22] GRADDOL, D. (2006). English Next. London: The British Council.

[23] IBN KHALDOUN, A. (1377). El Mukkadima.

[24] Webb, S. HOLFORD, J., HODGE, S., MILANA, M. and WALTER, R. (2017). Lifelong Learning for Quality Education. Exploring the Neglected Aspect of Sustainable Development. International Journal of Lifelong Education. 36 (5) 509-511.

[25] CHANG, J. (2006). Globalization and English in Chinese Higher Education. Oxford: Oxford Blackwell Publishing.

[26] BIRCH, G. J. and LIYANAGE, I. (2004). TESOL: Trojan Horse of Globalization. Research Gate. 93-102. 